\title{
A critical appraisal of atomoxetine in the management of ADHD
}

\author{
This article was published in the following Dove Press journal: \\ Therapeutics and Clinical Risk Management \\ 23 December 2015 \\ Number of times this article has been viewed
}

\author{
Ann C Childress \\ Center for Psychiatry and Behavioral \\ Medicine, Inc., Las Vegas, NV, USA
}

\begin{abstract}
Attention-deficit/hyperactivity disorder (ADHD) is a common neurobehavioral disorder beginning in childhood and often continuing into adulthood. A wealth of data shows that ADHD symptoms respond well to pharmacological treatment. Stimulant medications, including amphetamine and methylphenidate, are most commonly used to treat ADHD. However, with the approval of atomoxetine (Strattera ${ }^{\circledR}$, [ATX]) by the US Food and Drug Administration in late 2002, an effective non-stimulant option became available. The US Food and Drug Administration approved ATX for the treatment of ADHD in children, adolescents, and adults. Although the effect size of ATX is generally lower than that of stimulants, the American Academy of Child and Adolescent Psychiatry Practice Parameter for the treatment of ADHD lists ATX as a firstline treatment option. ATX is widely prescribed and accounted for $6 \%$ of the prescriptions of ADHD visits in the US in 2010. Numerous trials have found that ATX improves quality of life and emotional lability in addition to core ADHD symptoms. Although some improvement may be seen in a patient as early as one week after the initiation of treatment, ATX generally takes longer to have a full effect. The median time to response using $25 \%$ improvement in ADHD symptoms in pooled trials was 3.7 weeks. Data from these trials indicate that the probability of symptom improvement may continue to increase up to 52 weeks after treatment is initiated. ATX has been shown to be safe and effective in combination with stimulants. It has also been studied systematically in subjects with ADHD and comorbid oppositional defiant disorder, anxiety, depression, and substance use disorders. The mechanism of action of ATX, its efficacy, and adverse events reported in trials is reviewed.
\end{abstract}

Keywords: attention-deficit/hyperactivity disorder, Strattera, non-stimulants, pharmacotherapy

\section{Introduction}

Attention-deficit/hyperactivity disorder (ADHD) is a common neurobehavioral disorder beginning in childhood and often continuing into adulthood. The Diagnostic and Statistical Manual of Mental Disorders, Fifth Edition, defines ADHD as "a persistent pattern of inattention and/or hyperactivity-impulsivity that interferes with functioning or development." Lifetime prevalence for children and adolescents is estimated to be $9.5 \%$ in the $\mathrm{US}^{2}$ and $5.29 \%$ worldwide. ${ }^{3,4}$ For adults, prevalence in the US is $4.4 \%$ and $2.5 \%$ worldwide. ${ }^{5,6}$ ADHD symptoms cause significant functional impairment across a person's lifespan. Children with ADHD demonstrate lower academic performance and more problems with peers than children without the disorder. ${ }^{7}$ Adults with ADHD have more difficulties with psychosocial and neuropsychological functioning and lower levels of educational achievement and employment than adults without ADHD. ${ }^{8,9}$

Psychostimulants have been the standard of treatment for ADHD for more than 50 years. Although highly efficacious, concerns about abuse, dependence, tolerability, and slowing of growth may limit their use in some patients. In 2002, Strattera ${ }^{\circledR}$
Correspondence: Ann C Childress Center for Psychiatry and Behavioral Medicine, Inc., 735I Prairie Falcon Road, Suite 160, Las Vegas, NV 89128, USA

$\mathrm{Tel}+\mathrm{I} 7028380742$

Fax +l 7028386749

Email drann87@aol.com
Therapeutics and Clinical Risk Management 2016:12 27-39 (c) (i) (5) 2016 Childress. This work is published by Dove Medical Press Limited, and licensed under Creative Commons Attribution - Non Commercial (unported, v3.0) LY LC License. The full terms of the License are available at http://creativecommons.org/licenses/by-nc/3.0/. Non-commercial uses of the work are permitted without any further permission how to request permission may be found at: http://www.dovepress.com/permissions.php 
(atomoxetine $[\mathrm{ATX}]$ ) was the first non-stimulant medication approved for use in the treatment of ADHD. ${ }^{10}$ Since its initial approval in the US, ATX has been marketed in approximately 90 countries and is widely used, accounting for $6 \%$ of prescriptions written for ADHD treatment visits in the US in 2010. ${ }^{11}$ Data from more than a decade of use around the world are now available for ATX. This review will focus on the efficacy and tolerability of ATX in the treatment of ADHD.

On February 12, 2015 a PubMed search using the keywords atomoxetine and ADHD resulted in 969 references. Manuscript titles and abstracts were reviewed for inclusion. Double-blind, randomized controlled trials for all age groups were included. Open-label studies were included where relevant.

\section{Mechanism of action, pharmacokinetics, and dosing}

ATX is a white solid that is dispensed in capsules of 10, 18, $25,40,60,80$, and $100 \mathrm{mg}$. The mechanism of action of ATX is thought to be related to inhibition of the presynaptic norepinephrine transporter. ${ }^{10}$ Both norepinephrine and dopamine have been implicated in the pathophysiology of ADHD. ${ }^{12}$ ATX has a high water solubility and is well-absorbed after oral dosing. Bioavailability ranges from $63 \%-94 \% .{ }^{13}$ Blood levels are affected little by food. ${ }^{10}$ ATX is metabolized by the P450 CYP2D6 pathway and has a peak plasma concentration of 1-2 hours, with a half-life of about 5.2 hours in extensive metabolizers. ${ }^{13}$ In poor metabolizers, the plasma half-life of ATX is 21.6 hours. Subjects who are poor metabolizers of CYP2D6 drugs may have peak ATX plasma concentrations that are ten times higher than those of extensive metabolizers. The half-life, maximum plasma concentrations, and total drug exposure for ATX are similar for children, adolescents, and adults when values are corrected for body weight. ${ }^{14}$ Drugs such as fluoxetine, paroxetine, and quinidine which inhibit CYP2D6, cause increases in the plasma concentration of ATX and decrease elimination of ATX.$^{10}$ Poor metabolizers are more likely to achieve response at similar doses of ATX than extensive metabolizers. ${ }^{15}$ They are also more likely to experience increases in blood pressure, heart rate, and adverse events (AEs), such as tremor and decreased appetite, than extensive metabolizers.

\section{Abuse liability}

Data from a Rhesus monkey trial indicated that ATX lacks reinforcing effects and human abuse potential. ${ }^{16}$ In a human study, stimulant drug abusers did not prefer ATX significantly more than placebo. ${ }^{17}$

\section{Dosing}

Dosing of ATX in children was initially studied in an openlabel trial of 30 subjects aged 7-14 years. ATX was started at $10-20 \mathrm{mg}$ and titrated to optimal dose $(<90 \mathrm{mg})$ over 11 weeks. ${ }^{18}$ Mean final total daily dose was $1.9 \mathrm{mg} / \mathrm{kg} /$ day (range: $0.4-3.2 \mathrm{mg} / \mathrm{kg} /$ day). Core ADHD symptoms decreased significantly as measured by the investigator-scored ADHD Rating Scale-IV (ADHD-RS-IV), which is an 18-item scale using Diagnostic and Statistical Manual of Mental Disorders, Fourth Edition (DSM-IV) diagnostic criteria, from baseline to the end of the 11-week trial.

The maximum daily dose approved by the US FDA for children and adolescents who weigh $\leq 70 \mathrm{~kg}$ is $1.4 \mathrm{mg} / \mathrm{kg} /$ day; for children and adolescents who weigh $>70 \mathrm{~kg}$ and adults, it is $100 \mathrm{mg} /$ day. ${ }^{10}$ Studies using up to $2.4 \mathrm{mg} / \mathrm{kg} /$ day and $3.0 \mathrm{mg} / \mathrm{kg} /$ day have not shown an improved overall response in children or adolescents who did not respond to lower doses of ATX (1.2 to $1.8 \mathrm{mg} / \mathrm{kg} /$ day). ${ }^{19}$ When discontinuing ATX, tapering is not necessary as stopping the medication is not associated with acute discontinuation symptoms. ${ }^{20}$

For subjects with hepatic impairment, the dose should be reduced to $50 \%$ of the normal dose for those with moderate impairment, and to $25 \%$ for those with severe impairment. $^{21}$

The effects of a daily dosing regimen and speed of titration were evaluated in a post hoc analysis of 22 child/ adolescent and three adult ATX trials in subjects with ADHD. ${ }^{22}$ The time to the start of treatment-emergent AEs was significantly shorter in subjects who received once-aday versus twice-a-day dosing $(P \leq 0.007)$. Time to onset of decreased appetite, abdominal pain, and somnolence significantly decreased with fast titration in children and adults. Fast titration was defined as ATX $0.5 \mathrm{mg} / \mathrm{kg} /$ day $\times 7$ days, then ATX $1.2 \mathrm{mg} / \mathrm{kg} /$ day versus slow titration ATX $0.5 \mathrm{mg} / \mathrm{kg} /$ day $\times 7$ days, then ATX $0.8 \mathrm{mg} / \mathrm{kg} /$ day for 7 days, followed by ATX $1.2 \mathrm{mg} / \mathrm{kg} /$ day for children.

For adults, fast titration was defined as ATX $40 \mathrm{mg} /$ day $\times 3$ days then ATX $80 \mathrm{mg}$ /day. Slow titration was ATX $40 \mathrm{mg} /$ day $\times 7$ days then ATX $80 \mathrm{mg} /$ day. ${ }^{22}$ For adults, time to onset of insomnia was significantly shorter and lasted longer with twice-a-day dosing $(P<0.001)$ and fast titration compared with slow titration $(P \leq 0.001)$. The rates for decreased appetite, nausea, and vomiting were significantly greater for once-daily dosing than twice-daily dosing $(P<0.037)$.

Both once-daily morning and evening dosing regimens for ATX have been evaluated. In a trial of morning and evening ATX dosing compared to placebo in 288 children aged 6-12 years, ADHD-RS-IV total scores improved significantly 
during the 6-week trial $(P<0.001)$ for morning dosing while ADHD-RS-IV total scores for children with evening dosing was not significantly different from placebo. ${ }^{23}$ Mean changes for evening behavior using the Conners' Global Index-Parent Version (CGI-P) ratings were significantly better for morning- and evening-dosed ATX versus placebo $(P<0.001$ and $P<0.05$, respectively). Evening dosing with ATX was better tolerated than morning dosing.

\section{Efficacy \\ Children and adolescents}

Pooled data from multiple randomized trials indicate that ATX is equally effective in children and adolescents. ${ }^{24}$ No significant differences in response rates, time to response, rates of AEs, vital signs, weight, height, laboratory values, or ECG parameters were seen between groups. ADHD symptom scores at baseline were lower in adolescents than children. For AEs with treatment, children had higher rates of somnolence and headache. Table 1 summarizes pivotal efficacy trials.

In an early ATX study, 297 subjects aged 8-18 years who were diagnosed with ADHD using DSM-IV criteria participated in an 8-week double-blind, randomized, multicenter, placebo-controlled trial using three doses of
ATX. ${ }^{25}$ Subjects were randomized to receive a final dose of ATX $0.5 \mathrm{mg} / \mathrm{kg} / \mathrm{day}, 1.2 \mathrm{mg} / \mathrm{kg} /$ day, $1.8 \mathrm{mg} / \mathrm{kg} / \mathrm{day}$, or placebo. At study completion, the ADHD-RS-IV mean change from baseline was significant for the $1.2 \mathrm{mg} / \mathrm{kg} /$ day and $1.8 \mathrm{mg} / \mathrm{kg} /$ day groups compared to placebo $(P<0.001)$. There was no significant difference in efficacy between the $1.2 \mathrm{mg} / \mathrm{kg} /$ day and the $1.8 \mathrm{mg} / \mathrm{kg} /$ day doses.

A total of 291 (Study I, n=147 and Study II, n=144) children aged 7-12 years participated in two proof-ofconcept, 12-week, multicenter, double-blind, randomized, placebo-controlled trials. ${ }^{26}$ A methylphenidate (MPH) group was included to validate study design. Subjects naïve to stimulants were randomized to receive MPH, ATX, or placebo and subjects who had previous stimulant exposure were randomized to ATX or placebo. Dose titration was flexible with a maximum ATX of $2.0 \mathrm{mg} / \mathrm{kg} /$ day or $90 \mathrm{mg}$ in the ATX or placebo group, and $1.5 \mathrm{mg} / \mathrm{kg} / \mathrm{day}$ or MPH $60 \mathrm{mg}$ in the MPH, ATX, or placebo group. In both studies the mean ADHD-RS-IV decrease in baseline scores was significantly higher for the ATX groups compared to the placebo groups $(P<0.001)$.

In another large double-blind study, 171 subjects aged 6-16 years were randomized to once-daily ATX or placebo

Table I Summary of pivotal atomoxetine efficacy trials

\begin{tabular}{|c|c|c|c|c|}
\hline Author & Population & Study design & $\begin{array}{l}\text { Primary efficacy } \\
\text { measurement }\end{array}$ & Results \\
\hline Michelson et $\mathrm{al}^{25}$ & $\begin{array}{l}297 \text { subjects, } \\
\text { aged } 8-18 \text { years }\end{array}$ & $\begin{array}{l}\text { 8-week, double-blind, } \\
\text { randomized, placebo- } \\
\text { controlled trial }\end{array}$ & $\begin{array}{l}\text { ADHD-RS-IV mean } \\
\text { change from baseline to } \\
\text { endpoint ATX vs placebo }\end{array}$ & $\begin{array}{l}\mathrm{I} .2 \text { and } \mathrm{I} .8 \mathrm{mg} / \mathrm{kg} / \text { day ATX } \\
\text { groups superior to placebo } \\
(P<0.00 \mathrm{I})\end{array}$ \\
\hline Michelson et $\mathrm{al}^{27}$ & $\begin{array}{l}\text { I7I subjects, } \\
\text { aged } 6-16 \text { years }\end{array}$ & $\begin{array}{l}\text { 6-week, randomized, } \\
\text { double-blind, } \\
\text { placebo-controlled } \\
\text { trial }\end{array}$ & $\begin{array}{l}\text { Mean change in ADHD- } \\
\text { RS-IV total score at each } \\
\text { visit }\end{array}$ & $\begin{array}{l}\text { ATX superior to placebo } \\
(P<0.00 I) \text { beginning at week I; } \\
\text { effect size } 0.7 I\end{array}$ \\
\hline Spencer et $\mathrm{al}^{26}$ & $\begin{array}{l}291 \text { children, } \\
\text { aged } 7-12 \text { years }\end{array}$ & $\begin{array}{l}\text { Two I2-week } \\
\text { randomized, double- } \\
\text { blind, placebo- } \\
\text { controlled trials }\end{array}$ & $\begin{array}{l}\text { Mean change in ADHD- } \\
\text { RS-IV total score from } \\
\text { baseline to endpoint }\end{array}$ & $\begin{array}{l}\text { Significant improvement with } \\
\text { ATX }(P<0.00 \text { I }) \text { for each trial }\end{array}$ \\
\hline Kratochvil et $\mathrm{al}^{28}$ & $\begin{array}{l}93 \text { children, } \\
\text { aged } 5-6 \text { years }\end{array}$ & $\begin{array}{l}\text { 8-week double- } \\
\text { blind, randomized } \\
\text { controlled trial }\end{array}$ & $\begin{array}{l}\text { Mean change in ADHD- } \\
\text { RS-IV total score }\end{array}$ & $\begin{array}{l}\text { Significant improvement with } \\
\text { ATX vs placebo }(P<0.009)\end{array}$ \\
\hline Michelson et $\mathrm{al}^{33}$ & $\begin{array}{l}\text { Study I: } 280 \text { adults } \\
\text { and } \\
\text { Study II: } 256 \text { adults }\end{array}$ & $\begin{array}{l}\text { I0-week, } \\
\text { randomized, double- } \\
\text { blind, placebo- } \\
\text { controlled trial }\end{array}$ & $\begin{array}{l}\text { CAARS repeated } \\
\text { measures mixed model } \\
\text { analysis of post baseline } \\
\text { values }\end{array}$ & $\begin{array}{l}\text { ATX group significant } \\
\text { improvement vs placebo } \\
\text { Study I }(P=0.005) \\
\text { Study II }(P=0.002)\end{array}$ \\
\hline Adler et $\mathrm{al}^{36}$ & 501 adults & $\begin{array}{l}\text { 6-month, double- } \\
\text { blind, placebo- } \\
\text { controlled trial }\end{array}$ & $\begin{array}{l}\text { Mean change from } \\
\text { baseline to endpoint in } \\
\text { AISRS total score }\end{array}$ & $\begin{array}{l}\text { Significant improvement with } \\
\text { ATX vs placebo }(P=0.035)\end{array}$ \\
\hline Young et $\mathrm{al}^{37}$ & 502 adults & $\begin{array}{l}\text { 24-week, double- } \\
\text { blind, placebo- } \\
\text { controlled trial }\end{array}$ & $\begin{array}{l}\text { Change in CAARS total } \\
\text { scores at } 12 \text { and } 24 \text { weeks }\end{array}$ & $\begin{array}{l}\text { ATX significantly improved vs } \\
\text { placebo at I } 2 \text { weeks }(P<0.00 \mathrm{I}) \text {; } \\
\text { and at } 24 \text { weeks }(P<0.00 \mathrm{I})\end{array}$ \\
\hline
\end{tabular}

Abbreviations: ADHD, Attention-deficit/hyperactivity disorder; ADHD-RS-IV, ADHD Rating Scale-IV; CAARS, Conners' Adult ADHD Rating Scale; AISRS, Adult ADHD Investigator Symptom Rating Scale; ATX, atomoxetine; vs, versus. 
for 6 weeks. ${ }^{27}$ Initial target dose of ATX was $1.0 \mathrm{mg} / \mathrm{kg} / \mathrm{day}$. Subjects who had more than minimal ADHD symptoms at week 4 on the CGI scale had their ATX dose increased to $1.5 \mathrm{mg} / \mathrm{kg} /$ day. Significant improvement for ATX compared to placebo on the primary efficacy measure, the ADHDRS-IV, was seen at 1 week and continued to study completion. At the end of the trial, $59.5 \%$ of subjects in the ATX group compared to $31.3 \%$ of subjects in the placebo group had a decrease of $\geq 25 \%$ on the ADHD-RS-IV. Effect size of ATX was 0.71 .

ATX was also evaluated in young children (5-7 years old). A total of 93 subjects were dosed in an 8-week, randomized, double-blind, placebo-controlled trial of ATX.$^{28}$ Of these, 18 discontinued prior to completion including three who discontinued due to AEs (all of whom were on placebo). Mean final total daily dose was $1.4( \pm 0.4) \mathrm{mg} / \mathrm{kg} /$ day. Subjects who received ATX had significantly greater improvement in ADHD-RS-IV scores than subjects who received placebo $(P<0.009)$.

In a 7-week trial of ATX in a school setting, a total of 153 subjects aged 8-12 years diagnosed with ADHD were randomized to receive ATX up to $1.8 \mathrm{mg} / \mathrm{kg} /$ day or placebo once daily in a $2: 1$ ratio. ${ }^{29}$ Using the ADHD-RS-IV, the child's primary teacher was interviewed via telephone by a study investigator. Subjects treated with ATX had a significant decrease in ADHD symptoms $(P=0.001)$. Onset of drug effect was seen during the first week of treatment. The effect size was 0.63.

ATX has also been studied in other countries. In a randomized, double-blind, placebo-controlled trial in Taiwan, 106 children and adolescents aged 6-16 years were treated with ATX $(n=72)$ once daily, or placebo $(n=34) .{ }^{30}$ Subjects in the ATX group had significantly greater improvement in ADHD symptoms based on ADHD-RS-IV ratings and Conner's Parent and Teacher Rating Scales-Revised: Short Form. For the ADHD-RS-IV, effect size was 0.70.

ATX has been shown to improve morning and evening behaviors associated with ADHD. The Daily Parent Ratings of Evening and Morning Behavior-Revised scale was administered to parents of 197 children aged 6-12 years who had ADHD. ${ }^{31}$ Subjects were randomized to receive ATX up to $1.8 \mathrm{mg} / \mathrm{kg}$ /day (maximum dose $120 \mathrm{mg} /$ day) or placebo. Improvement in the Daily Parent Ratings of Evening and Morning Behavior-Revised scale total score was noted during the first day of dosing and continued to be significant at endpoint.

\section{Adults}

Multiple double-blind, placebo-controlled trials have been conducted in adults with ADHD. In an early double-blind, placebo crossover study, Spencer et al found that eleven out of 21 subjects with ADHD had a $\geq 30 \%$ improvement at the end of a 3-week treatment period with ATX compared with two of 21 at the end of a 3 -week placebo period $(P<0.01) .{ }^{32}$ Average dose of ATX was $76 \mathrm{mg} /$ day.

Two large, identical 10-week, randomized, double-blind, placebo-controlled studies of ATX in adults found ATX superior to placebo in reducing ADHD symptoms on the Conners' Adult ADHD Rating Scale (CAARS). A total of 280 adults in Study I and 256 adults in Study II were randomized to receive ATX or placebo after a 2-week placebo lead-in phase. ${ }^{33}$ ATX subjects were dosed twice daily, beginning at $60 \mathrm{mg} /$ day and was increased up to 120/day mg based on response. In both studies, the mean improvement in the CAARS total ADHD symptom score from baseline to end point was significantly larger for the ATX versus placebo groups, $P=0.005$ and $P=0.002$, respectively.

Subjects who participated in the 10 -week treatment study were able to enter an open-label ATX study. ${ }^{33}$ In the open-label trial, dosing of ATX started at $25 \mathrm{mg}$ twice-daily and was titrated based on response to a maximum dose of $160 \mathrm{mg} /$ day. A total of 385 subjects entered the open label trial. By the end of 97 weeks, 125 (32.6\%) subjects were continuing in the trial. ${ }^{34}$ At 221 , weeks only 69 subjects completed the trial. ${ }^{35}$ The majority of early withdrawals were due to lack of efficacy 101 (26.3\%), personal conflict or decision $66(17.2 \%)$, lost to follow-up $(15.9 \%)$, or AE $7(12.2 \%)$. During treatment, the CAARS total ADHD symptom score decreased $30.2 \%(P<0.001)$.

In a 6-month, double-blind, placebo-controlled trial, 501 adults were randomized to receive ATX $(n=250)$ or placebo $(n=251)$ in the morning. ${ }^{36}$ A total of 94 subjects in the ATX group and 112 subjects in the placebo group completed the study. The change in Adult ADHD Investigator Symptom Rating Scale scores was significantly greater for the ATX group at the end of 6 months than for placebo, $P=0.035$.

In another large, double-blind, placebo-controlled trial, 502 subjects were randomized to receive placebo $(n=234)$ or ATX 60 to $100 \mathrm{mg}(\mathrm{n}=268)$ after a 2-week open-label titration to $80 \mathrm{mg}$ of ATX. CAARS scores decreased significantly for subjects on ATX compared to those on placebo at 12 weeks $(P<0.001)$, as well as at 24 weeks $(P<0.001$, effect size 0.57$).{ }^{37}$ A CAARS decrease of $25 \%$ or more was seen in $68 \%$ of subjects receiving ATX and $42 \%$ of those receiving placebo.

Cunill et al completed a systematic review and meta-analysis on twelve randomized, controlled trials $(3,375$ subjects) comparing ATX to placebo in adults with ADHD. ${ }^{38}$ They calculated the standardized mean differences using 
clinician rated scales at -0.40 - a modest effect size. They noted that few subjects discontinued due to lack of efficacy (5\% with ATX and 6\% with placebo). However, a larger percentage of subjects discontinued because of AEs while taking ATX (13\%) compared to 5\% while on placebo. They concluded that the evidence to recommend ATX to treat $\mathrm{ADHD}$ in adults is weak because of the AE profile.

Asherson et al evaluated the efficacy in Eli Lilly-sponsored adult trials comparing ATX to placebo, including six shortterm (10- to 16-weeks) and three long-term (6 months) trials. ${ }^{39}$ Response rates of $\geq 30 \%$ on the CAARS ratings and CGI of ADHD-Severity $\leq 3$ (mildly ill) were significantly greater for ATX versus placebo during both the short- and long-term trials. Response rates defined as $\geq 40 \%$ improvement of CAARS ratings were also significantly greater for ATX versus placebo during all trials (for all of these measures, $P<0.001)$.

In a review of all adult ADHD trials, the most common AEs included nausea, dry mouth, decreased appetite, insomnia, and erectile dysfunction. Mean increase in heart rate $(+5.2 \mathrm{bpm})$ and blood pressure systolic $(+2 \mathrm{mmHg})$, and diastolic $(+1.9 \mathrm{mmHg})$ occurred. ${ }^{40}$

\section{Relapse prevention}

A randomized, double-blind, placebo-controlled withdrawal study was completed with 416 subjects aged 6-15 years with ADHD who completed 12 weeks of open-label treatment with ATX $\leq 1.8 \mathrm{mg} / \mathrm{kg} /$ day and had at least a $25 \%$ decrease on the ADHD-RS-IV. ${ }^{41}$ Subjects were assigned to ATX or placebo for up to 9 months. Relapse was defined as an increase in the ADHD-RS-IV total score to $90 \%$ of the subject's baseline value and an increase (worsening) in CGI of ADHD-Severity score of at least two points from week 12. Mean number of days ( \pm standard deviation [SD]) to relapse was significantly longer in the ATX group, $217.7( \pm 5.52)$ days, than the placebo group, $146.1( \pm 7.24)$ days, $P<0.001$.

Data suggest that subjects who respond to ATX acutely at doses of $1.2-1.8 \mathrm{mg} / \mathrm{kg} /$ day may be able to maintain improvement on a lower long-term maintenance dose of ATX. In a maintenance trial of ATX responders, 229 subjects aged 6-16 years were randomized to receive their acute response dose or $0.5 \mathrm{mg} / \mathrm{kg} /$ day. ${ }^{42}$ Relapse rates, defined as a return to $\geq 90 \%$ of baseline score at study entry for two consecutive visits, were not significantly different between groups $(P=0.924)$. In addition, there was no significant difference between the high dose and low dose groups in the number of subjects who no longer met response criteria of $\geq 40 \%$ decrease from baseline ADHD-RS-IV scores $(P=0.321)$.
Time to response for ATX is longer than that of stimulants. Pooled data from three open-label studies found that the median time to improvement $(25 \%$ reduction of symptoms on the ADHD-RS-IV) was 3.7 weeks, but remission (ADHD-RS-IV $\leq 18$ and CGI-Improvement $\leq 2$ ) did not occur until a median of 14.3 weeks. The probabilities of robust improvement ( $40 \%$ reduction in ADHD-RS-IV scores) were $47 \%$ by 4 weeks of treatment, $76 \%$ at 12 weeks, $85 \%$ at 26 weeks, and $96 \%$ at 52 weeks. ${ }^{43}$

\section{Sleep}

The effects of ATX dosed twice daily were compared with those of MPH dosed three-times daily in a randomized, double-blind, crossover trial of 85 children diagnosed with ADHD. ${ }^{44}$ Sleep onset latency was significantly longer for patients taking MPH (39.2 minutes versus 12.1 minutes, $P<0.001)$. Subjects reported that they slept better and it was easier to get up in the morning while on ATX. Parents reported their children were less irritable, easier to get up and get ready in the morning, had less difficulty getting ready for bed, and had less difficulty falling asleep while on ATX compared with $\mathrm{MPH}^{44}$

\section{Emotional lability}

Emotional impulsivity, emotional dysregulation, or emotional lability is characterized by quick changes in mood and is a common feature associated with ADHD. ${ }^{45}$ In two large, adult ADHD trials described in Michelson et al, ${ }^{33}$ the Wender-Reimherr Adult Attention Deficit Disorder Scale (WRAADDS) was administered as a secondary outcome measure. ${ }^{33}$ In addition to questions about core ADHD symptoms defined by the DSM- $I V$, the WRAADDS also queries emotional items (temper, affective lability, and emotional over-reactivity). ${ }^{46} \mathrm{~A}$ post hoc analysis was performed comparing the sum of the emotional items on the WRAADDS at baseline and endpoint. A score of 7 or higher was chosen as indicative of emotional dysregulation. Of the 529 subjects enrolled, $170(32 \%)$ met criteria for emotional dysregulation at baseline. Subjects randomized to ATX showed significantly greater improvement in emotional lability than those on placebo $(P=0.001)$.

\section{ATX and stimulants}

Several trials have compared ATX with stimulants. In one randomized, placebo-controlled, double-blind crossover trial, children and adolescents aged 6-16 years were randomized to receive ATX up to $1.8 \mathrm{mg} / \mathrm{kg} /$ day ( $\mathrm{n}=222)$, osmotically released (OROS) MPH up to $54 \mathrm{mg} /$ day $(\mathrm{n}=220)$ or placebo $(\mathrm{n}=74) .{ }^{47}$ Response was defined as $\geq 40 \%$ decrease in symptoms on the 
ADHD-RS-IV. Response rate for OROS MPH was 56\%, ATX was $45 \%$, and placebo was $24 \%$. There were 70 subjects who did not respond to OROS MPH. Of these, 30 (43\%) who were switched to ATX, responded. Of the 69 who did not respond to ATX, 29 (42\%) had previously responded to OROS MPH.

ATX was compared with immediate-release MPH in a double-blind study outside the US. ${ }^{48}$ Subjects aged 6-16 years were randomized to receive ATX $(0.8-1.8 \mathrm{mg} / \mathrm{kg} / \mathrm{day}$, $\mathrm{n}=164)$ or MPH twice a day $(0.2-0.6 \mathrm{mg} / \mathrm{kg} /$ day, $\mathrm{n}=166)$ for 8 weeks. The primary outcome measure was the number of subjects who achieved a response of $\geq 40 \%$ on the ADHDRS-IV. In this trial there was no significant difference in response rates $(P=0.404)$.

ATX was compared with OROS MPH in a randomized, double-blind, community-based trial in 1,323 subjects aged 6-12 years. ${ }^{49}$ Subjects were randomized 2:1 to receive OROS MPH or ATX for 3 weeks. At the end of the study the ADHD-RS-IV mean decrease from baseline was 20.24 for OROS MPH and 16 for ATX $(P<0.001)$.

ATX was compared with mixed amphetamine (AMPH) salts extended release (MAS XR) in children aged 6-12 years in a double-blind, placebo-controlled, forced-dose laboratory classroom study. ${ }^{50}$ After screening, 217 subjects were randomized to 18 days of double-blind dosing with ATX or MAS XR. The target dose of ATX was $1.2 \mathrm{mg} / \mathrm{kg} /$ day and of MAS XR was $30 \mathrm{mg} /$ day. The primary efficacy variable was the Swanson, Kotkin, Agler, M-Flynn and Pelham (SKAMP) rating scale deportment score. The SKAMP is designed to be administered by trained raters who observe subjects in a structured classroom setting. The mean change from baseline was significantly better for MAS XR on the SKAMP deportment sub-scale than for ATX $(P<0.0001)$.

ATX was compared with lisdexamfetamine (LDX) in a 9-week, randomized, double-blind, head-to-head trial of 267 children and adolescents with ADHD aged 6-17 years. ${ }^{51}$ Although both treatments were effective, the difference between LDX and ATX least squares mean change from baseline to endpoint was significantly greater for LDX. For the ADHD-RS-IV total score, the difference between the treatments was $-6.5(-9.3$ to $-3.60 ; P<0.001)$, effect size 0.56 . The time to response was also significantly shorter for LDX than ATX. The percentage of subjects having $\geq 50 \%$ response on the ADHD-RS-IV was $41.7 \%$ for LDX and $23.7 \%$ for ATX by week $9 .{ }^{52}$

\section{Tolerability problems with stimulants}

Patients who have an inadequate response or tolerability issues with MPH or AMPH may benefit from a switch to
ATX. In one study, 62 subjects $(51.6 \%$ on MPH and $48.4 \%$ on AMPH) aged 6-17 years who complained of inadequate response $(53.2 \%)$ or intolerability $(46.8 \%)$ were started on ATX and had their stimulant discontinued. ${ }^{53}$ ATX was titrated to $1.2 \mathrm{mg} / \mathrm{kg} /$ day and continued for 5 weeks. Investigator ADHD-RS-IV scores decreased significantly from baseline to endpoint $(P<0.001)$.

\section{ATX partial responders}

Some ATX partial responders may benefit from the addition of $\mathrm{MPH}$ to their ADHD treatment regimen. In an open-label trial, 50 subjects aged 6-17 years who had a CGI-Improvement of "minimally improved" after 4 weeks of treatment with ATX were given OROS MPH for three additional weeks up to a maximum dose of $54 \mathrm{mg} /$ day. ${ }^{54}$ Subjects treated with the combination of ATX and OROS MPH had a 40\% decrease in ADHD-RS-IV total scores from week 4 to the end of the trial $(P<0.0001)$. The combination of OROS MPH and ATX resulted in higher rates of insomnia, irritability, and loss of appetite than ATX only. ${ }^{55}$ No clinically significant changes were noted in blood pressure, heart rate, or electrocardiogram parameters.

\section{Executive functioning}

ATX has been shown to improve executive functioning significantly more than placebo. In a double-blind, randomized, placebo-controlled trial of ATX, 445 adults with ADHD aged 18-30 years with ADHD completed the Behavior Rating Inventory of Executive Function-Adult at the baseline visit, after 5 weeks of treatment, and at the end of the 12-week trial. ${ }^{56}$ The Behavior Rating Inventory of Executive Function-Adult is a 75-item self-report questionnaire that measures executive functioning and self-regulation. It produces an overall score, the Global Executive Composite (GEC) and two index scores; the Behavioral Regulation Index (BRI) and Metacognitive Index (MI). At the baseline visit, the GEC, BRI, and MI T-scores were $\geq 60$ (two SDs above the standardized mean) for more than $90 \%$ of subjects in the ATX group and placebo groups. There were statistically significant improvements from baseline to the end of the trial in the ATX versus placebo groups in the GEC, BRI, and MI scores. The effect size for the GEC scores was -0.32 .

\section{Quality of life measures}

Improvement in ADHD symptoms in subjects treated with ATX has been associated with improvement in quality of life (QoL) measures in children, adolescents, and adults. Data were collected from several double-blind, placebo-controlled 
trials of ATX in children and adolescents using the Child Health Questionnaire 50-item Parent Form. The 50-item scale assesses both physical and psychosocial functioning in twelve domain subscales. When baseline parent ratings were compared with responses from two 8-week and one 7-week trials, significant improvement was noted for Role Limitations-Emotional/Behavioral, Behavior, Mental Health, Self-esteem, Parental Impact-emotional, Parental Impacttime, Family Activities, and the Psychosocial Summary scores. ${ }^{57,58}$ Effect size for the Psychosocial Summary score was 0.55 . Although scores were improved at end of treatment, they continued to be below normative values indicating continued impairment.

During long-term treatment of up to 24 months with ATX, Child Health Questionnaire 50-item Parent Form scores did not improve significantly for most domains compared with scores at the end of acute treatment. The only significant improvement was found in the Parental Impact-emotional subscale $(P=0.003) .{ }^{59}$

The impact of ATX on QoL in adult subjects has also been measured. The 36-item Medical Outcomes Study short-form health survey was used in a six-week, double-blind, placebocontrolled trial of 205 adults who completed both baseline and endpoint measures. ${ }^{60}$ The 36-item Medical Outcomes Study short-form health survey consists of 36 questions assessing physical functioning, bodily pain, role limitations due to physical problems, general health perceptions, mental health, social functioning, and vitality. Scores at endpoint were significantly improved for mental health, emotional role limitations, social functioning, and vitality $(P<0.001)$, bodily pain $(P=0.021)$, and general health $(P=0.008)$.

The Adult ADHD QoL Measure (AAQoL) is a validated, 29-item, patient-rated instrument designed to assess healthrelated QoL over the previous 2 weeks using a five-point Likert scale which ranges from "not at all/never" to "extremely/ very often". The scale has four subscales which include Life Productivity, Psychological Health, Life Outlook, and Relationships. ${ }^{61}$ The AAQoL has been used in several studies with ATX. ${ }^{62,63}$ The AAQoL was used to evaluate QoL changes in 328 adult subjects treated with ATX or placebo during an 8-week, randomized, double-blind, placebo-controlled trial. ${ }^{62}$ From baseline to week 8 , subjects on ATX significantly improved on all measures compared to those on placebo $(P<0.0001)$. Effect size for the total score was -1.11 .

The Endicott Work Productivity Scale (EWPS) is a 25-item self-report questionnaire that assesses work productivity. Both the EWPS and AAQoL were functional outcome measures in a 6-month trial consisting of a double-blind, placebo-controlled treatment phase followed by a 4-month open-label extension using ATX up to $100 \mathrm{mg} .{ }^{63}$ Subjects were aged $18-50$ years who were employed $\geq 20$ hours per week. A total of 271 were randomized to receive ATX and 139 were randomized to placebo. Improvement on the AAQoL was significant compared to placebo at the 6-month endpoint for only the Life Outlook subscale. Although significant improvements on the EWPS were seen after 1 month of treatment, there were no significant changes at the end of 6 months between ATX and placebo.

Treatment with ATX has not been shown to significantly improve marital or parenting functioning. ${ }^{64}$

\section{ADHD and comorbid disorders Oppositional defiant disorder}

A recent meta-analysis of 25 double-blind, randomized, controlled trials in children and adolescents found that ATX decreased oppositional defiant disorder (ODD) symptoms. ${ }^{65}$ It is unclear whether subjects with ADHD and ODD need higher doses of ATX to respond. In one trial, subjects with ADHD and ODD were found to respond to ATX at $1.8 \mathrm{mg} / \mathrm{kg} / \mathrm{day}$, but not at $1.2 \mathrm{mg} / \mathrm{kg}$ day. ${ }^{66}$ In other trials, a dose-response relationship in subjects with comorbid ODD has not been seen. ${ }^{67}$ Hazell et al did not find a correlation between ATX plasma concentration and ADHD or ODD symptom improvement. ${ }^{68}$

\section{Depression and anxiety}

ATX is effective in decreasing symptoms of anxiety in subjects with comorbid ADHD and anxiety. In a randomized, double-blind, placebo-controlled, parallel-design trial, 176 children and adolescents aged 8-17 years who had ADHD and generalized anxiety disorder, separation anxiety disorder and/or social phobia, were given ATX or placebo. Subjects were given ATX up to $1.8 \mathrm{mg} / \mathrm{kg} /$ day or placebo for 10 weeks. ${ }^{69}$ At the end of the study, ADHD and anxiety were significantly improved in subjects on ATX compared to placebo ( $P<0.001$ for ADHD and $P=0.011$ for anxiety).

ATX has also been studied in adults with ADHD and social anxiety. A total of 442 adults participated in a randomized, double-blind, placebo-controlled, parallel-design trial of ATX ( $\mathrm{n}=224)$ up to $100 \mathrm{mg} /$ day and placebo $(\mathrm{n}=218){ }^{70}$ Liebowitz Social Anxiety Scale total scores decreased from baseline to the end of the trial, $P<0.001$. All subscale scores including Performance Fear, Social Fear, and Social Avoidance, also decreased significantly in the ATX group. CAARS scores also improved significantly more for ATX subjects $(P<0.001)$. 
ATX does not appear to be effective in the treatment of Major Depressive Disorder comorbid with ADHD. In a 9-week trial, 142 subjects aged $12-18$ years who met $D S M-I V$ criteria for ADHD and Major Depressive Disorder were randomly assigned to ATX or placebo. ${ }^{71}$ ADHD symptoms improved significantly. However, there was no significant improvement in depression as measured by the Children's Depression Rating Scale-Revised when ATX was compared to placebo $(P=0.34)$.

A total of 173 subjects aged 7-17 years with ADHD and depression or anxiety were randomized to receive fluoxetine $20 \mathrm{mg}$ or placebo for three weeks. ${ }^{72}$ ATX was then added for the last 5 weeks of the trial. Reductions in depression, anxiety, and ADHD symptoms were significant for both treatment groups $(P<0.001)$. For subjects with depression, there were significantly more responders in the combined treatment group than in the ATX only group.

\section{Autism spectrum disorders}

In one small, double-blind, crossover study of 16 children aged 5-15 years with autism spectrum disorders and ADHD, subjects were randomized to receive either ATX or placebo for 6 weeks, then placebo or ATX for 6-weeks separated by a 1-week washout. ${ }^{73}$ The hyperactivity subscale of the Aberrant Behavior Checklist was the primary outcome measure. Response to ATX was significantly better than placebo for hyperactivity $(P=0.43$, effect size $\mathrm{d}=0.90)$. AEs which were significantly different than placebo included upset stomach, nausea/vomiting, tiredness/fatigue, and racing heart. All 16 subjects reported mild stomach upset or nausea/vomiting while on ATX. One subject (7\%) discontinued secondary to intolerability.

In a larger parallel, double-blind, placebo-controlled study, 97 subjects aged 6-17 years with ADHD and autism spectrum disorders were assigned treatment with ATX $1.2 \mathrm{mg} / \mathrm{kg} /$ day or placebo for 8 weeks. ${ }^{74}$ ADHD-RS-IV total scores, hyperactivity/impulsivity, and inattentive subscale scores improved significantly for the ATX group $(P<0.001)$. AEs occurring more frequently in the ATX group included nausea, decreased appetite, and early morning awakening. Of these subjects, 88 were treated with open-label ATX for 20 additional weeks. ${ }^{75}$ ADHD symptoms continued to decrease significantly.

\section{Alcohol use disorders}

ATX has been shown to be effective in reducing ADHD symptoms in adult subjects with alcohol abuse and/or dependence. ${ }^{76} \mathrm{~A}$ total of 147 subjects participated in a randomized, double-blind, placebo-controlled trial of ATX and placebo. Although ADHD symptoms improved, there were no significant differences between ATX and placebo groups in time-to-relapse of heavy drinking. The number of cumulative heavy drinking days was decreased by $26 \%$ in the ATX group $(P=0.023)$.

Thurstone et $\mathrm{al}^{77}$ did not find a difference between substance use changes in 70 adolescents with at least one nonnicotine substance use disorder when ATX was compared to placebo. Both groups received motivational interviewing and cognitive behavioral therapy. Likewise, no significant differences in marijuana use outcomes were found in 38 marijuana-dependent adult subjects diagnosed with ADHD randomized to receive either ATX or placebo along with motivational interviewing for 12 weeks. $^{78}$

\section{AEs}

A summary of common AEs is contained in Table 2.

\section{Cardiovascular}

Small, statistically significant effects on mean systolic blood pressure in adults and diastolic blood pressure in children and adolescents were noted in ATX trials. In short-term trials, increases in pulse rate were noted for all groups. No clinically significant changes in vital signs were reported in long-term trials $\geq 4$ years in children and adolescents. ${ }^{79}$ Likewise, no statistically significant changes from baseline QTc have been seen. ${ }^{79,80}$ However, $1.2 \%$ (6/507) of subjects treated $\geq 4$ years developed prolonged QTc using Fridericia's formula (QTcF) defined as $\geq 450 \mathrm{msec}$ in males and $\geq 470 \mathrm{msec}$ in females. No children or adolescents had a QTcF $\geq 500 \mathrm{msec}$.

A retrospective review of 20,995 adults starting on ATX found no increased risk of serious cardiovascular events compared to age-matched subjects who were not taking ADHD medications. ${ }^{81}$

Table 2 Atomoxetine adverse events $\geq 5 \%$ in clinical trials

\begin{tabular}{lllll}
\hline Children & & & Adults \\
\cline { 1 - 2 } Adverse event & Percentage & & Adverse event & Percentage \\
\hline Nausea & 10 & Constipation & 8 \\
Vomiting & 11 & & Dry mouth & 20 \\
Fatigue & 8 & Nausea & 26 \\
Decreased appetite & 16 & Decreased appetite & 16 \\
Abdominal pain & 18 & Dizziness & 8 \\
Somnolence & 11 & Erectile dysfunction & 8 \\
Headache & 19 & Urinary hesitation & 6 \\
Dizziness & 5 & Abdominal pain & 7 \\
Irritability & 6 & Fatigue & 10 \\
& & Insomnia & 15 \\
& & Irritability & 5 \\
\hline
\end{tabular}

Note: Data used with permission of Eli Lilly and Company. ${ }^{10}$ 


\section{Liver function}

Liver function tests have been routinely obtained in clinical trials of ATX. Of 7,961 subjects who participated in clinical trials prior to March 1, 2006, 41 cases of elevated liver function tests were identified using the criteria of liver enzyme elevations of $\geq 2$ times the upper limit of normal or total bilirubin elevations of $\geq 1.5$ the upper limit of normal. ${ }^{82}$ None of these met Hy's law criteria of alanine transaminase (ALT) $\geq 3$ times the upper limit of normal and total bilirubin of $\geq 2$ times the upper limit of normal. None progressed to liver failure. However, three cases of liver injury probably related to ATX have been reported in patients taking the drug outside of clinical trials.

\section{Growth}

Long-term growth data is available for children and adolescents treated with ATX for $>4$ years. ${ }^{79}$ Height and weight results are available for 508 subjects treated with ATX for a mean of 5.3 years. For this group, mean increase in weigth was $21.7 \mathrm{~kg}$ (standard deviation $12.0 \mathrm{~kg}$ ) which corresponded to an increase in weight percentile of 3.3 compared with normative data from National Center for Health Statistics. For height, the mean increase was $20.9 \mathrm{~cm}( \pm 11.0 \mathrm{~cm})$. This corresponded to a decrease of 0.8 percentile.

\section{Development}

Treatment with ATX had no statistically significant impact on sexual development as measured by Tanner stages during an 18-month, placebo-controlled, multicenter trial in subjects aged $6-15$ years. $^{83}$

\section{Tics}

ATX was evaluated in a double-blind, placebo-controlled study in 148 subjects aged 7-17 years who had ADHD and a comorbid tic disorder ${ }^{84}$ Improvement in tics with ATX compared to placebo was not significant on the primary efficacy measure; the Yale Global Tic Severity Scale (YGTSS) total score.

ATX was used in a double-blind, placebo-controlled trial in subjects aged 7-17 years with ADHD and comorbid Tourette Syndrome. ${ }^{85}$ The primary efficacy measure again was the mean change from baseline to endpoint in the YGTSS. A total of 117 subjects were randomized to either ATX $(n=61)$ or placebo $(n=56)$. On the YGTSS, the ATX group showed a significant decrease in baseline tic severity compared to placebo at endpoint.

\section{Suicidality}

A meta-analysis of suicide-related events during the acute phases of double-blind, placebo-controlled trials of ATX in children, adolescents, and adults was completed by searching the ATX AE database. The meta-analysis included 3,883 children/adolescents and 3,365 adult subjects. ${ }^{86}$ The occurrence of suicidal ideation or behaviors in children and adolescents on ATX was $0.37 \%$ and on placebo was $0.07 \%$. For adults the occurrence was $0.11 \%$ during ATX treatment and $0.12 \%$ during placebo treatment. The risk was not statistically significantly greater than placebo in pediatric or adult subjects. There were no completed suicides in any of the ATX studies.

\section{Discussion}

A wealth of data is available for ATX indicating that it is effective in the treatment of ADHD in patients aged $\geq 5$ years. A recent meta-analysis reviewed 25 double-blind, randomized controlled trials with ATX which included 3,928 children and adolescents. In these trials, ATX was significantly better than placebo in relieving ADHD symptoms with $44.4 \%$ of subjects in the ATX group achieving $\geq 40 \%$ improvement versus $21.4 \%$ of those receiving placebo. ${ }^{65}$ However, in these trials $39.4 \%$ of subjects receiving ATX had symptom improvement of $<25 \%$.

Multiple randomized trials have compared immediaterelease MPH (five trials), OROS MPH (three trials), and both immediate-release MPH and OROS MPH (one trial), and ATX ${ }^{87} \mathrm{~A}$ meta-analysis of these nine trials included a total of 2,762 subjects with durations of 3-10 weeks concluded that MPH and ATX have similar efficacy and acceptability. Effect size favored MPH but the difference was not statistically significant. Sub-group analysis found a significant standardized mean difference in favor of OROS MPH versus ATX whereas there were no significant standardized mean differences between IR MPH and ATX.

Fewer data are available comparing AMPH to ATX; however AMPH appears to be more effective. Trials included a laboratory classroom trial with MAS-XR versus ATX and 9-week, head-to-head trial with LDX versus ATX. ${ }^{49}$ All of the comparison trials with stimulants were of short duration and there is evidence that ATX may take several months to reach its full effect.

A meta-analysis comparing stimulants to non-stimulants found the effect sizes of long-acting stimulants to be significantly higher for than for non-stimulants. ${ }^{88}$

Another meta-analysis of adult trials with ATX concluded that the effect was modest and the evidence for use was weak because of discontinuations due to AEs. ${ }^{37}$ There is evidence that speed of dose titration and dosing schedule (once daily versus twice daily) influences AEs, with subjects 
who undergo a slower dose titration having fewer and less severe AEs. Slow titration and once-daily dosing may be especially important in the adult population where the risk:benefit ratio is higher.

ATX is associated with significant improvements on QoL measures in children, adolescents, and adults. However, gains noted during acute treatment are not necessarily further improved during long-term treatment. Comorbid disorders including ODD and anxiety also improve with ATX treatment but depression and substance use disorders do not.

Data also indicate that a switch to ATX may be useful for patients who cannot tolerate or do not respond to stimulants. Furthermore, the addition of MPH may improve response in subjects who have only partial improvement on ATX. ATX is also a good alternative for athletes who have ADHD. The National Collegiate Athletic Association guidelines require a therapeutic use exemption for athletes who take psychostimulants, and other athletic governing bodies prohibit use of psychostimulants during competition. ${ }^{89}$

The use of ATX in the treatment of ADHD with comorbid tics may lessen tic severity. However, the data are mixed. One study found no improvement on the YGTSS with ATX use in subjects with comorbid tics. ${ }^{84}$ Another trial found improvement in the YGTSS with the use of ATX. ${ }^{85}$

ATX has no impact on long-term growth or sexual development. Safety data indicate that extended treatment with ATX does not cause clinically significant cardiovascular changes and the occurrence of suicidal ideation is not increased while taking ATX.

\section{Conclusion}

Although ATX may be less effective than stimulant medication, it is safe and useful for both acute and long-term treatment of ADHD in children, adolescents, and adults. ADHD treatment guidelines recommend ATX as a first-line treatment option and it may be especially helpful for patients who have ADHD and comorbid anxiety. ATX should also be considered when patients with previous stimulant exposure have had efficacy or tolerability concerns. A history of substance abuse with patient or family members may also make ATX a viable treatment option in that population.

When developing a treatment plan for patients who have ADHD, the need for quick response should also be considered when choosing a medication. Although there are early improvements in ADHD symptoms with the use of ATX, the time to maximal response for ATX makes it less useful than stimulants, which have a rapid onset of effect.

\section{Disclosure}

The author reports the following disclosures: Shire Pharmaceuticals, Inc. for consultant, speaker, research support, and writing support; Pfizer for research support, speaker, advisory board, and writing support; Noven for research support and advisory board; NextWave Pharmaceuticals for research support, consultant, advisory board, and writing support; Lilly USA, LLC for research support; Forest Research Institute for research support; Otsuka for research support; Sunovion for research support and consultant; Ironshore for consultant, research support, advisory board, and writing support; Rhodes for consultant, research support, advisory board, and writing support; Theravance for research support; Neurovance for advisory board, research support, and consultant; Neos for consultant, research support, advisory board, and writing support; Arbor for consultant, research support, speaker, advisory board, and writing support; Tris for research support; Purdue for research support; Lundbeck for research support; and Alcobra for research support. The author did not receive any funding for the preparation of this manuscript.

\section{References}

1. American Psychiatric Association, American Psychiatric Association. DSM-5 Task Force. Diagnostic and Statistical Manual of Mental Disorders: DSM-IV. 5th ed. Washington, D.C.: American Psychiatric Association; 2013.

2. Pray LA, Institute of Medicine (U.S.). Food Forum. Relationships among the brain, the digestive system, and eating behavior: workshop summary. Washington, DC: National Academies Press (US); 2015.

3. Increasing prevalence of parent-reported attention-deficit/hyperactivity disorder among children - United States, 2003 and 2007. MMWR Morb Mortal Wkly Rep. 2010;59(44):1439-1443.

4. Polanczyk G, de Lima MS, Horta BL, Biederman J, Rohde LA. The worldwide prevalence of ADHD: a systematic review and metaregression analysis. Am J Psychiatry. 2007;164(6):942-948.

5. Kessler RC, Adler L, Barkley R, et al. The prevalence and correlates of adult ADHD in the United States: results from the National Comorbidity Survey Replication. Am J Psychiatry. 2006;163(4):716-723.

6. Simon V, Czobor P, Bálint S, Mészáros A, Bitter I. Prevalence and correlates of adult attention-deficit hyperactivity disorder: meta-analysis. Br J Psychiatry. 2009;194(3):204-211.

7. Efron D, Sciberras E, Anderson V, et al. Functional status in children with ADHD at age 6-8: a controlled community study. Pediatrics. 2014; 134(4):e992-e1000.

8. Biederman J, Petty CR, Woodworth KY, Lomedico A, Hyder LL, Faraone SV. Adult outcome of attention-deficit/hyperactivity disorder: a controlled 16-year follow-up study. J Clin Psychiatry. 2012;73(7): 941-950.

9. Gjervan B, Torgersen T, Nordahl HM, Rasmussen K. Functional impairment and occupational outcome in adults with ADHD. J Atten Disord. 2012;16(7):544-552.

10. Strattera ${ }^{\circledR}$ (atomoxetine hydrochloride). US prescribing information. Eli Lilly and Company, Indianapolis, IN; 2015.

11. Garfield CF, Dorsey ER, Zhu S, et al. Trends in attention deficit hyperactivity disorder ambulatory diagnosis and medical treatment in the United States, 2000-2010. Acad Pediatr. 2012;12(2):110-116.

12. Arnsten AF. Catecholamine influences on dorsolateral prefrontal cortical networks. Biol Psychiatry. 2011;69(12):e89-e99. 
13. Sauer JM, Ring BJ, Witcher JW. Clinical pharmacokinetics of atomoxetine. Clin Pharmacokinet. 2005;44(6):571-590.

14. Witcher JW, Long A, Smith B, et al. Atomoxetine pharmacokinetics in children and adolescents with attention deficit hyperactivity disorder. J Child Adolesc Psychopharmacol. 2003;13(1):53-63.

15. Michelson D, Read HA, Ruff DD, Witcher J, Zhang S, McCracken J. CYP2D6 and clinical response to atomoxetine in children and adolescents with ADHD. J Am Acad Child Adolesc Psychiatry. 2007;46(2): 242-251.

16. Wee S, Woolverton WL. Evaluation of the reinforcing effects of atomoxetine in monkeys: comparison to methylphenidate and desipramine. Drug Alcohol Depend. 2004;75(3):271-276.

17. Jasinski DR, Faries DE, Moore RJ, Schuh LM, Allen AJ. Abuse liability assessment of atomoxetine in a drug-abusing population. Drug Alcohol Depend. 2008;95(1-2):140-146.

18. Spencer T, Biederman J, Heiligenstein J, et al. An open-label, dose-ranging study of atomoxetine in children with attention deficit hyperactivity disorder. J Child Adolesc Psychopharmacol. 2001;11(3):251-265.

19. Kratochvil CJ, Michelson D, Newcorn JH, et al. High-dose atomoxetine treatment of ADHD in youths with limited response to standard doses. J Am Acad Child Adolesc Psychiatry. 2007;46(9):1128-1137.

20. Wernicke JF, Adler L, Spencer T, et al. Changes in symptoms and adverse events after discontinuation of atomoxetine in children and adults with attention deficit/hyperactivity disorder: a prospective, placebo-controlled assessment. J Clin Psychopharmacol. 2004;24(1):30-35.

21. Chalon SA, Desager JP, Desante KA, et al. Effect of hepatic impairment on the pharmacokinetics of atomoxetine and its metabolites. Clin Pharmacol Ther. 2003;73(3):178-191.

22. Wietecha LA, Ruff DD, Allen AJ, Greenhill LL, Newcorn JH. Atomoxetine tolerability in pediatric and adult patients receiving different dosing strategies. J Clin Psychiatry. 2013;74(12):1217-1223.

23. Block SL, Kelsey D, Coury D, et al. Once-daily atomoxetine for treating pediatric attention-deficit/hyperactivity disorder: comparison of morning and evening dosing. Clin Pediatr (Phila). 2009;48(7):723-733.

24. Wilens TE, Kratochvil C, Newcorn JH, Gao H. Do children and adolescents with ADHD respond differently to atomoxetine? J Am Acad Child Adolesc Psychiatry. 2006;45(2):149-157.

25. Michelson D, Faries D, Wernicke J, et al. Atomoxetine in the treatment of children and adolescents with attention-deficit/hyperactivity disorder: a randomized, placebo-controlled, dose-response study. Pediatrics. 2001;108(5):E83.

26. Spencer T, Heiligenstein JH, Biederman J, et al. Results from 2 proof-of-concept, placebo-controlled studies of atomoxetine in children with attention-deficit/hyperactivity disorder. J Clin Psychiatry. 2002;63(12):1140-1147.

27. Michelson D, Allen AJ, Busner J, et al. Once-daily atomoxetine treatment for children and adolescents with attention deficit hyperactivity disorder: a randomized, placebo-controlled study. Am J Psychiatry. 2002;159(11):1896-1901.

28. Kratochvil CJ, Vaughan BS, Stoner JA, et al. A double-blind, placebocontrolled study of atomoxetine in young children with ADHD. Pediatrics. 2011;127(4):e862-e868.

29. Weiss M, Tannock R, Kratochvil C, et al. A randomized, placebocontrolled study of once-daily atomoxetine in the school setting in children with ADHD. J Am Acad Child Adolesc Psychiatry. 2005;44(7): 647-655.

30. Gau SS, Huang YS, Soong WT, et al. A randomized, double-blind, placebo-controlled clinical trial on once-daily atomoxetine in Taiwanese children and adolescents with attention-deficit/hyperactivity disorder. J Child Adolesc Psychopharmacol. 2007;17(4):447-460.

31. Kelsey DK, Sumner CR, Casat CD, et al. Once-daily atomoxetine treatment for children with attention-deficit/hyperactivity disorder, including an assessment of evening and morning behavior: a doubleblind, placebo-controlled trial. Pediatrics. 2004;114(1):e1-e8.

32. Spencer T, Biederman J, Wilens T, et al. Effectiveness and tolerability of tomoxetine in adults with attention deficit hyperactivity disorder. $\mathrm{Am}$ J Psychiatry. 1998;155(5):693-695.
33. Michelson D, Adler L, Spencer T, et al. Atomoxetine in adults with ADHD: two randomized, placebo-controlled studies. Biol Psychiatry. 2003;53(2):112-120.

34. Adler LA, Spencer TJ, Milton DR, Moore RJ, Michelson D. Long-term, open-label study of the safety and efficacy of atomoxetine in adults with attention-deficit/hyperactivity disorder: an interim analysis. $J$ Clin Psychiatry. 2005;66(3):294-299.

35. Adler LA, Spencer TJ, Williams DW, Moore RJ, Michelson D. Longterm, open-label safety and efficacy of atomoxetine in adults with ADHD: final report of a 4-year study. J Atten Disord. 2008;12(3):248-253.

36. Adler LA, Spencer T, Brown TE, et al. Once-daily atomoxetine for adult attention-deficit/hyperactivity disorder: a 6-month, double-blind trial. J Clin Psychopharmacol. 2009;29(1):44-50.

37. Young JL, Sarkis E, Qiao M, Wietecha L. Once-daily treatment with atomoxetine in adults with attention-deficit/hyperactivity disorder: a 24-week, randomized, double-blind, placebo-controlled trial. Clin Neuropharmacol. 2011;34(2):51-60.

38. Cunill R, Castells X, Tobias A, Capellà D. Atomoxetine for attention deficit hyperactivity disorder in the adulthood: a meta-analysis and metaregression. Pharmacoepidemiol Drug Saf. 2013;22(9):961-969.

39. Asherson P, Bushe C, Saylor K, Tanaka Y, Deberdt W, Upadhyaya H. Efficacy of atomoxetine in adults with attention deficit hyperactivity disorder: an integrated analysis of the complete database of multicenter placebo-controlled trials. $J$ Psychopharmacol. 2014;28(9): $837-846$.

40. Camporeale A, Porsdal V, De Bruyckere K, et al. Safety and tolerability of atomoxetine in treatment of attention deficit hyperactivity disorder in adult patients: an integrated analysis of 15 clinical trials. J Psychopharmacol. 2015;29(1):3-14.

41. Michelson D, Buitelaar JK, Danckaerts M, et al. Relapse prevention in pediatric patients with $\mathrm{ADHD}$ treated with atomoxetine: a randomized, double-blind, placebo-controlled study. J Am Acad Child Adolesc Psychiatry. 2004;43(7):896-904.

42. Newcorn JH, Michelson D, Kratochvil CJ, Allen AJ, Ruff DD, Moore RJ. Low-dose atomoxetine for maintenance treatment of attention-deficit/ hyperactivity disorder. Pediatrics. 2006;118(6):e1701-e1706.

43. Dickson RA, Maki E, Gibbins C, Gutkin SW, Turgay A, Weiss MD. Time courses of improvement and symptom remission in children treated with atomoxetine for attention-deficit/hyperactivity disorder: analysis of Canadian open-label studies. Child Adolesc Psychiatry Ment Health. 2011;5:14.

44. Sangal RB, Owens J, Allen AJ, Sutton V, Schuh K, Kelsey D. Effects of atomoxetine and methylphenidate on sleep in children with ADHD. Sleep. 2006;29(12):1573-1585.

45. Barkley RA, Fischer M. The unique contribution of emotional impulsiveness to impairment in major life activities in hyperactive children as adults. J Am Acad Child Adolesc Psychiatry. 2010;49(5):503-513.

46. Reimherr FW, Marchant BK, Strong RE, et al. Emotional dysregulation in adult ADHD and response to atomoxetine. Biol Psychiatry. 2005;58(2):125-131.

47. Newcorn JH, Kratochvil CJ, Allen AJ, et al. Atomoxetine and osmotically released methylphenidate for the treatment of attention deficit hyperactivity disorder: acute comparison and differential response. $\mathrm{Am}$ J Psychiatry. 2008;165(6):721-730.

48. Wang Y, Zheng Y, Du Y, et al. Atomoxetine versus methylphenidate in paediatric outpatients with attention deficit hyperactivity disorder: a randomized, double-blind comparison trial. Aust $N$ Z J Psychiatry. 2007;41(3):222-230.

49. Kemner JE, Starr HL, Ciccone PE, Hooper-Wood CG, Crockett RS. Outcomes of OROS methylphenidate compared with atomoxetine in children with ADHD: a multicenter, randomized prospective study. Adv Ther. 2005;22(5):498-512.

50. Wigal SB, McGough JJ, McCracken JT, et al. A laboratory school comparison of mixed amphetamine salts extended release (Adderall $\mathrm{XR}$ ) and atomoxetine (Strattera) in school-aged children with attention deficit/hyperactivity disorder. J Atten Disord. 2005;9(1):275-289. 
51. Dittmann RW, Cardo E, Nagy P, et al. Efficacy and safety of lisdexamfetamine dimesylate and atomoxetine in the treatment of attention-deficit/ hyperactivity disorder: a head-to-head, randomized, double-blind, phase IIIb study. CNS Drugs. 2013;27(12):1081-1092.

52. Dittmann RW, Cardo E, Nagy P, et al. Treatment response and remission in a double-blind, randomized, head-to-head study of lisdexamfetamine dimesylate and atomoxetine in children and adolescents with attentiondeficit hyperactivity disorder. CNS Drugs. 2014;28(11):1059-1069.

53. Quintana H, Cherlin EA, Duesenberg DA, et al. Transition from methylphenidate or amphetamine to atomoxetine in children and adolescents with attention-deficit/hyperactivity disorder - a preliminary tolerability and efficacy study. Clin Ther. 2007;29(6):1168-1177.

54. Wilens TE, Hammerness P, Utzinger L, et al. An open study of adjunct OROS-methylphenidate in children and adolescents who are atomoxetine partial responders: I. Effectiveness. J Child Adolesc Psychopharmacol. 2009;19(5):485-492.

55. Hammerness P, Georgiopoulos A, Doyle RL, et al. An open study of adjunct OROS-methylphenidate in children who are atomoxetine partial responders: II. Tolerability and pharmacokinetics. J Child Adolesc Psychopharmacol. 2009;19(5):493-499.

56. Adler LA, Clemow DB, Williams DW, Durell TM. Atomoxetine effects on executive function as measured by the BRIEF - $\mathrm{a}$ in young adults with ADHD: a randomized, double-blind, placebo-controlled study. PLoS One. 2014;9(8):e104175.

57. Matza LS, Rentz AM, Secnik K, et al. The link between health-related quality of life and clinical symptoms among children with attentiondeficit hyperactivity disorder. J Dev Behav Pediatr. 2004;25(3): 166-174.

58. Perwien AR, Faries DE, Kratochvil CJ, Sumner CR, Kelsey DK, Allen AJ. Improvement in health-related quality of life in children with ADHD: an analysis of placebo controlled studies of atomoxetine. $J$ Dev Behav Pediatr. 2004;25(4):264-271.

59. Perwien AR, Kratochvil CJ, Faries DE, Vaughan BS, Spencer T, Brown RT. Atomoxetine treatment in children and adolescents with attention-deficit hyperactivity disorder: what are the long-term healthrelated quality-of-life outcomes? J Child Adolesc Psychopharmacol. 2006;16(6):713-724.

60. Adler LA, Sutton VK, Moore RJ, et al. Quality of life assessment in adult patients with attention-deficit/hyperactivity disorder treated with atomoxetine. J Clin Psychopharmacol. 2006;26(6):648-652.

61. Brod M, Johnston J, Able S, Swindle R. Validation of the adult attention-deficit/hyperactivity disorder quality-of-life Scale (AAQoL): a disease-specific quality-of-life measure. Qual Life Res. 2006;15(1): $117-129$.

62. Matza LS, Johnston JA, Faries DE, Malley KG, Brod M. Responsiveness of the Adult Attention-Deficit/Hyperactivity Disorder Quality of Life Scale (AAQoL). Qual Life Res. 2007;16(9):1511-1520.

63. Adler LA, Spencer TJ, Levine LR, et al. Functional outcomes in the treatment of adults with ADHD. J Atten Disord. 2008;11(6):720-727.

64. Wietecha L, Young J, Ruff D, Dunn D, Findling RL, Saylor K. Atomoxetine once daily for 24 weeks in adults with attention-deficit/hyperactivity disorder (ADHD): impact of treatment on family functioning. Clin Neuropharmacol. 2012;35(3):125-133.

65. Schwartz S, Correll CU. Efficacy and safety of atomoxetine in children and adolescents with attention-deficit/hyperactivity disorder: results from a comprehensive meta-analysis and metaregression. $J$ Am Acad Child Adolesc Psychiatry. 2014;53(2):174-187.

66. Newcorn JH, Spencer TJ, Biederman J, Milton DR, Michelson D. Atomoxetine treatment in children and adolescents with attention-deficit/ hyperactivity disorder and comorbid oppositional defiant disorder. $J$ Am Acad Child Adolesc Psychiatry. 2005;44(3):240-248.

67. Biederman J, Spencer TJ, Newcorn JH, et al. Effect of comorbid symptoms of oppositional defiant disorder on responses to atomoxetine in children with ADHD: a meta-analysis of controlled clinical trial data. Psychopharmacology (Berl). 2007;190(1):31-41.
68. Hazell P, Becker K, Nikkanen EA, et al. Relationship between atomoxetine plasma concentration, treatment response and tolerability in attention-deficit/hyperactivity disorder and comorbid oppositional defiant disorder. Atten Defic Hyperact Disord. 2009;1(2):201-210.

69. Geller D, Donnelly C, Lopez F, et al. Atomoxetine treatment for pediatric patients with attention-deficit/hyperactivity disorder with comorbid anxiety disorder. J Am Acad Child Adolesc Psychiatry. 2007; 46(9):1119-1127.

70. Adler LA, Liebowitz M, Kronenberger W, et al. Atomoxetine treatment in adults with attention-deficit/hyperactivity disorder and comorbid social anxiety disorder. Depress Anxiety. 2009;26(3):212-221.

71. Bangs ME, Emslie GJ, Spencer TJ, et al. Efficacy and safety of atomoxetine in adolescents with attention-deficit/hyperactivity disorder and major depression. J Child Adolesc Psychopharmacol. 2007; 17(4):407-420.

72. Kratochvil CJ, Newcorn JH, Arnold LE, et al. Atomoxetine alone or combined with fluoxetine for treating ADHD with comorbid depressive or anxiety symptoms. J Am Acad Child Adolesc Psychiatry. 2005; 44(9):915-924.

73. Arnold LE, Aman MG, Cook AM, et al. Atomoxetine for hyperactivity in autism spectrum disorders: placebo-controlled crossover pilot trial. J Am Acad Child Adolesc Psychiatry. 2006;45(10):1196-1205.

74. Harfterkamp M, van de Loo-Neus G, Minderaa RB, et al. A randomized double-blind study of atomoxetine versus placebo for attention-deficit/ hyperactivity disorder symptoms in children with autism spectrum disorder. J Am Acad Child Adolesc Psychiatry. 2012;51(7):733-741.

75. Harfterkamp M, Buitelaar JK, Minderaa RB, van de Loo-Neus G, van der Gaag RJ, Hoekstra PJ. Long-term treatment with atomoxetine for attention-deficit/hyperactivity disorder symptoms in children and adolescents with autism spectrum disorder: an open-label extension study. J Child Adolesc Psychopharmacol. 2013;23(3):194-199.

76. Wilens TE, Adler LA, Weiss MD, et al. Atomoxetine treatment of adults with ADHD and comorbid alcohol use disorders. Drug Alcohol Depend. 2008;96(1-2):145-154.

77. Thurstone C, Riggs PD, Salomonsen-Sautel S, Mikulich-Gilbertson SK. Randomized, controlled trial of atomoxetine for attention-deficit/ hyperactivity disorder in adolescents with substance use disorder. $J \mathrm{Am}$ Acad Child Adolesc Psychiatry. 2010;49(6):573-582.

78. McRae-Clark AL, Carter RE, Killeen TK, Carpenter MJ, White KG, Brady KT. A placebo-controlled trial of atomoxetine in marijuanadependent individuals with attention deficit hyperactivity disorder. $\mathrm{Am}$ J Addict. 2010;19(6):481-489.

79. Donnelly C, Bangs M, Trzepacz P, et al. Safety and tolerability of atomoxetine over 3 to 4 years in children and adolescents with ADHD. J Am Acad Child Adolesc Psychiatry. 2009;48(2):176-185.

80. Wernicke JF, Faries D, Girod D, et al. Cardiovascular effects of atomoxetine in children, adolescents, and adults. Drug Saf. 2003;26(10): 729-740.

81. Schelleman H, Bilker WB, Kimmel SE, et al. Amphetamines, atomoxetine and the risk of serious cardiovascular events in adults. PLoS One. 2013;8(1):e52991.

82. Bangs ME, Jin L, Zhang S, et al. Hepatic events associated with atomoxetine treatment for attention-deficit hyperactivity disorder. Drug Saf. 2008;31(4):345-354.

83. Trzepacz PT, Spencer TJ, Zhang S, Bangs ME, Witte MM, Desaiah D. Effect of atomoxetine on Tanner stage sexual development in children and adolescents with attention deficit/hyperactivity disorder: 18-month results from a double-blind, placebo-controlled trial. Curr Med Res Opin. 2011;27 Suppl 2:45-52.

84. Allen AJ, Kurlan RM, Gilbert DL, et al. Atomoxetine treatment in children and adolescents with ADHD and comorbid tic disorders. Neurology. 2005;65(12):1941-1949.

85. Spencer TJ, Sallee FR, Gilbert DL, et al. Atomoxetine treatment of ADHD in children with comorbid Tourette syndrome. $J$ Atten Disord. 2008;11(4):470-481. 
86. Bangs ME, Wietecha LA, Wang S, Buchanan AS, Kelsey DK. Metaanalysis of suicide-related behavior or ideation in child, adolescent, and adult patients treated with atomoxetine. J Child Adolesc Psychopharmacol. 2014;24(8):426-434.

87. Hanwella R, Senanayake M, de Silva V. Comparative efficacy and acceptability of methylphenidate and atomoxetine in treatment of attention deficit hyperactivity disorder in children and adolescents: a meta-analysis. BMC Psychiatry. 2011;11:176.
88. Faraone SV, Glatt SJ. A comparison of the efficacy of medications for adult attention-deficit/hyperactivity disorder using meta-analysis of effect sizes. J Clin Psychiatry. 2010;71(6):754-763.

89. Perrin AE, Jotwani VM. Addressing the unique issues of student athletes with ADHD. J Fam Pract. 2014;63(5):E1-E9.

\section{Publish your work in this journal}

Therapeutics and Clinical Risk Management is an international, peerreviewed journal of clinical therapeutics and risk management, focusing on concise rapid reporting of clinical studies in all therapeutic areas outcomes, safety, and programs for the effective, safe, and sustained use of medicines. This journal is indexed on PubMed Central, CAS,
EMBase, Scopus and the Elsevier Bibliographic databases. The manuscript management system is completely online and includes a very quick and fair peer-review system, which is all easy to use. Visit http://www.dovepress.com/testimonials.php to read real quotes from published authors.

Submit your manuscript here: http://www.dovepress.com/therapeutics-and-clinical-risk-management-journal 